\title{
EXPERIMENT IN EARLY GREEK PHILOSOPHY AND MEDICINE
}

Anyone that attempts to tackle the question of the role of experiment in Greek science must first come to terms with the extensive modern literature on the subject, and what strikes one first about this literature is that ever since the Novum Organum of Bacon (1620) much of it has been highly polemical in tone. Bacon's judgement is well known: 'Atque ex philosophiis istis Graecorum, et derivationibus earum per particulares scientias, jam per tot annorum spatia vix unum experimentum adduci potest, quod ad hominum statum levandum et juvandum spectet, et philosophiae speculationibus ac dogmatibus vere acceptum referri possit.'I Against Aristotle in particular Bacon adopts a different line of attack, for he concedes that in some of Aristotle's works references to experiments are to be found, but accuses Aristotle of twisting the data of experience to fit his preconceived opinions. According to Bacon, then, Aristotle was more blameworthy than his modern adherents who neglected the data of experience entirely: "Ille enim prius decreverat, neque experientiam ad constituenda decreta et axiomata rite consuluit; sed postquam pro arbitrio suo decrevisset, experientiam ad sua placita tortam circumducit et captivam; ut hoc etiam nomine magis accusandus sit, quam sectatores ejus moderni (scholasticorum philosophorum genus) qui experientiam omnino deseruerunt.'2 Now there were, of course, good reasons why a seventeenthcentury scientist should react strongly against contemporary Aristotelianism. But similar exaggerations mar much of what was said about Greek science in general, and Aristotle's contribution in particular, by nineteenth-century historians of science. G. H. Lewes 3 quotes John Playfair's Dissertation, prefixed to the 1842 edition of the Encyclopaedia Britannica, as typifying the view prevailing in the mid-nineteenth century on the subject of the physical science of the Greeks and the reasons for its shortcomings. 'Extreme credulity disgraced the speculations of men who, however ingenious, were little acquainted with the laws of nature, and unprovided with the great criterion by which the evidence of testimony can alone be examined. Though observations were sometimes made, experiments were never instituted; and philosophers who were little attentive to the facts which spontaneously offered, did not seek to increase their number by artificial combinations.'4 In more modern discussions of this topic, too, the view has often been expressed that there is a fundamental distinction between ancient and modern science in that the ancients failed to employ the experimental method. J. O. Thomson, for example, put it that 'the Greeks were nearly always too ready to theorize, and had little of the modern will to collect and sift facts, or of the instruments and techniques necessary for this purpose: they tried to explain things without first studying and describing them properly, preferring instead to

1 Novum Organum, 1, 73.

$=$ Op. cit. 1,63 .

3 Aristotle, $A$ Chapter from the History of Science (London, 1864), p. 49.

$4 \mathrm{~J}$. Playfair, 'Dissertation... Exhibiting a general view of the progress of mathematical and physical science, since the revival of lerters in Europe', Encyclopaedia Britannica (7th ed., 1842), 1, Pp. 453 ff. 
analyse their own words and notions. So they initiated science but failed to sustain it, and never disengaged 'physics' from the general philosophy in which it began. There was a fatal neglect of detail and experiment and practical application, partly because most craftsmanship was left to slaves. Thus modern science, which rests on experiment, is in a sense not really continuous with ancient.'

Many other commentators have laid a similar emphasis on the failure of the Greeks to use experiment, or at least on their failure to use it systematically. ${ }^{2}$ On the other hand what one may call the 'positivist' school of interpretation has adopted a very different view on this question. Burnet, as is well known, attempted to defend the Greeks against the charge that they made no use of experiment. "The rise of the experimental method dates from the time when the medical schools began to influence the development of philosophy, and accordingly we find that the first recorded experiment of a modern type is that of Empedocles with the klepsydra.' 3 'It is inconceivable', Burnet went on, 'that an inquisitive people should have applied the experimental method in a single case without extending it to other problems', and elsewhere he argued that the reason why we have so little information about their observations and experiments is that "nearly all that we know on this subject comes from compilations and manuals composed centuries later, by men who were not themselves interested in science, and for readers who were even less so'. ${ }^{4}$ According to Burnet, then, 'if we can point to indubitable examples of the use of experiment and observation, we are justified in supposing that there were others of which we know nothing because they did not happen to interest the compilers on whom we are dependent', and a similar line of argument has been used both by Heidel 5 and, in more recent years, by Blüh. ${ }^{6}$

Several of the theses which have been maintained by either side in this controversy seem implausible or exaggerated, but to examine these in further detail would serve no useful purpose. There is, however, one important point which I hope emerges from the quotations I have given, and that is that modern commentators have shown a remarkable tendency to generalize on the question of whether or not the Greeks

I History of Ancient Geography (Cambridge, 1948), p. 94 .

2 A number of authorities are cited by Thomson, op. cit. p. 94, n. I and addenda p. 40r. More recently H. D. P. Lee, for example, in his introduction to the Loeb edition of Aristotle's Meteorologica (1952), p. xxvii, puts it that the experimental method eluded the Greeks: 'They observed but they did not experiment, and between observation and experiment there is a fundamental difference, which it is essential to recognize if the history of Greek thought is to be understood.' Compare the rather more cautious judgement of Sambursky, The Physical World of the Greeks, trans. M. Dagut (London, 1956), p. 2: 'With very few exceptions, the Ancient Greeks throughout a period of eight hundred years made no attempt at systematic experimentation.'

${ }^{3}$ Early Greek Philosophy (4th ed., London, 1948), p. 27.

4 Essays and Addresses (London, 1929), pp. 253 f. (cf. Cornford's remarks in Principium Sapientiae, Cambridge, 1952, p. 4).

5 The Heroic Age of Science (Baltimore, 1933), pp. $78 \mathrm{f}$., and later in Hippocratic Medicine, its Spirit and Method (New York, 1941), pp. $96 \mathrm{ff}$.

'In an article entitled 'Did the Greeks perform experiments?' in American Journal of Physics, xvir (1949), pp. $3^{8} 4 \mathrm{ff}$. On the topic as a whole cf. also L. Edelstein, 'Recent Trends in the Interpretation of Ancient Science', Journal of the History of Ideas, XIII (1952), Pp. 573 ff.; B. Farrington, 'The Greeks and the Experimental Method', Discovery, xvinl (1957), PP. 68 f., and V. P. Zubov, 'Beobachtung und Experiment in der antiken Wissenschaft', das Aliertum, v (1959), pp. $223 \mathrm{ff}$. 
experimented. Much of the discussion has been carried on as if the important thing was to decide the answer to this global question, and in attempting to settle this question one way or the other it has too often been forgotten that experimentation is of varying usefulness and relevance in different fields of scientific investigation, or even on different problems within the same field: indeed the role of experimentation may also be said to vary (in certain respects) at different levels of scientific development, that is according to the level of knowledge attained in a particular field at a particular time. To my mind, then, the question that needs to be asked is not the global one 'did the Greeks experiment?', nor even 'how far did the Greeks recognize the value of the experimental method?' Rather we should ask the more concrete, and at the same time much more difficult, questions 'what experiments were open to the Greeks on different problems or in different branches of science which they did not perform?' and on the other hand 'what tests did they actually carry out, in different fields, and with what success?' To these questions there is, of course, no simple yes or no answer. Rather we must try to assess the Greek performance in each department of science, indeed on each problem, independently, and to do this generally requires a thorough knowledge not merely of the contributions made in a particular field at different stages in antiquity, but also of the history of subsequent developments, that is of how thought developed on the subject in modern, post-Renaissance times.

Of course the extent of the subject I have outlined precludes anything like a full, let alone an exhaustive, treatment here, and I shall confine myself to making certain tentative suggestions concerning some of the problems which occur when we consider the earliest period of Greek science, that is, roughly speaking, from the sixth to the fourth century B.C. I shall take in turn each of the main departments of inquiry on which the earliest Greek investigators were engaged, and consider what evidence there is in our extant sources (principally the Presocratics, the Hippocratic Corpus and Aristotle) which will enable us to answer the two questions I have propounded.

The first point that may be made is the obvious one that much of the speculative effort of the earliest Greek natural philosophers was concentrated on a department of science which, strictly speaking, is not experimental at all: 1 mean, of course, astronomy. Astronomers can and do attempt to verify, by further observations, the predictions they make on the basis of theories or hypotheses, but in the nature of things they cannot conduct experiments, that is they cannot vary or govern the conditions of the objects they are observing. Ancient astronomy is, no doubt, in certain respects less rigorously empirical, more aprioristic, than modern, but how far we can talk of a fundamental difference in method between the two is more difficult to decide. While many of the explanations which Aristotle, for instance, put forward are, we should say, highly arbitrary, it is worth recalling that on more than one occasion he draws on the results obtained from many years of observations by Egyptian and Babylonian astronomers. ${ }^{1}$ that a passage in the Meteorologica suggests that his own observations extended, in some cases, over a period of fifty years, ${ }^{2}$ and that in a striking passage in the de Caelo, where he introduces one of his more fanciful explanations of a highly

Cael. 292a, 7 ff.; Mete. 343b, 9 ff. and $28 \mathrm{ff}$., and cf. also Cael. $270 b, 13 \mathrm{ff}$.

2 Mete. $372 a, 28 \mathrm{f}$. (referring to the rare occurrence of moon rainbows). 
obscure problem, ${ }^{\text {T }}$ he prefaces his account with this disclaimer: 'Perhaps to try to give an explanation about some things, or about everything without exception, may seem to indicate a high degree of simple-mindedness or a high degree of zeal. But', he goes on, 'this objection is not always just: one should consider the reason for speaking, and also what kind of conviction is being aimed at, whether merely human or something stronger. Whenever anyone lights upon more exact proofs, then we must be grateful to the discoverer, but for the present we must state what seems plausible.'2 However, my immediate point is not that in assessing the work of early Greek astronomers we should weigh against the obvious dogmatic and teleological features their use of empirical data 3 and certain passages in which they draw attention to the tentative nature of some of their theories, but rather this, that to speak of a "failure to conduct experiments' in this field would be quite inappropriate.

One may, perhaps, go further. If in astronomy it was physically impossible for the Greeks to carry out experiments, the same also applied for them, at least, in a large part of what they called 'meteorology'. Nowadays, it is true, it is possible to manufacture a lightning-flash artificially. But that the Greeks did not attempt to do so is hardly surprising (they got no further than noticing certain examples of static electricity, such as the attraction of amber when rubbed). For the Greeks most of the problems of 'meteorology', the nature and causes of lightning and thunder, meteors, winds, earthquakes and so on, were beyond the reach of direct experimental investigation. But if the theories put forward in this field by the Presocratics and later writers are generally highly dogmatic and speculative, this is not to say that no attempt whatsoever was made to adduce empirical support for some such doctrines. I have in mind the occasions when the explanation of an obscure natural phenomenon was illustrated or supported by an appeal to an analogy drawn from familiar experience. The comparison between the flash of lightning and the flash made by an oar or some such object on striking the water, which is mentioned by Aristotle at Mete. 370a, roff., seems to have been used by Anaximenes to back a theory originally advanced by Anaximander concerning the nature of lightning (namely that it is due to a cloud being split by the force of wind). ${ }^{4}$ Aristotle himself, in his account of thunder, compares it with the crackling of logs in a fire, attributing both phenomena to the 'dry exhalation'.5 And when he tackles the question of whether shooting-stars are actual projectiles, or whether this phenomenon is due to a train of fire passing rapidly from one thing to another, he draws on two analogies: either, he suggests, it may be like what happens when an unlit lamp is placed below another one which is alight and the

'Cael. B, ch. $5,2876,22 \mathrm{ff}$. The problem in question is why the heavens revolve in one direction rather than the other, or, as we should put it, why the earth revolves on its axis in one direction rather than the other (so far as I know, the problem has still not been solved).

${ }^{2}$ Cael. $2876,28 \mathrm{ff}$. There is a similar disclaimer at Cael. B, ch. 12, 291 b, $24 \mathrm{ff}$., where Aristotle discusses the problem of why some of the heavenly bodies have 'complex', others 'simple' motions.

${ }^{3}$ Sambursky, op. cit. pp. 50 ff., has drawn attention to the improvement of astronomical measurements that took place in the Greek period, instancing the increasing accuracy of the approximations which were made of the length of the solar year.

4 Aet. III, 3, 1-2; DK, 12A 23, 13 ^17.

5 Mete. $369 a, 29 \mathrm{ff}$. 
lower lamp is lit by a flame travelling rapidly downwards from the upper one, or else the shooting star may be a solid body forced downwards under pressure, and here he compares them with such objects as the stones of fruit being shot out from between the fingers, in order to illustrate how things may move, under pressure, in a direction contrary to their natural tendency. I Now many of the illustrations used by Greek writers to suggest or support explanations of meteorological phenomena might strike us as rather far-fetched, though this is not always the case: one might cite, for example, the passage in which Aristotle explains why we see the flash of lightning before we hear the sound of the thunder by referring to the experience of watching a ship at sea, where the oars are already going back again by the time the sound of their striking the water reaches us. ${ }^{2}$ But the point I should like to suggest is that in 'meteorology', where direct experimental investigation was often physically impossible, the appeal to

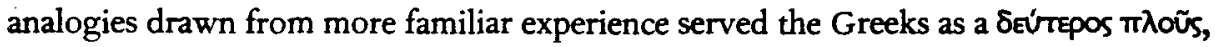
a next best method, indeed in many cases the only empirical method open to them. Moreover some of the illustrations they use refer not to well-known facts or common experience, but to quite rare phenomena, and in certain instances it seems that the analogy may even have involved the deliberate undertaking of a piece of research. If we take the illustration of the two lamps which Aristotle uses to suggest one of two possible explanations for the phenomena of shooting-stars, it is fairly clear that Aristotle himself had observed quite closely the way in which one lamp may be lit from another: 'the speed with which this happens', he notes at Mete. $342 a$, $5 \mathrm{ff}$., 'is extraordinary, and it resembles the projection of a missile, rather than fire passing from one thing to another'. And a second passage which shows how fine may be the distinction between an illustration drawn from familiar experience, and a deliberate piece of research, comes in Aristotle's discussion of the rainbow (Mete. $\Gamma$, ch. 4): there one of the illustrations which he adduces to support his suggestion that the rainbow is due to a reflection caused by minute drops of water is what happens when a man sprinkles water in a room which is so placed that it faces the sun and is partly illuminated by it and partly in shadow. 'Then if one man sprinkles water in the room, another standing outside sees a rainbow at the place where the sun's rays stop and the shadow begins.' 3 The invention of prisms was necessary before the spectrum could be fully investigated under strict experimental conditions. ${ }^{4}$ But it is apparent that an early stage the Greeks exploited their knowledge of rainbows formed under other, artificial conditions, in trying to explain the meteorological phenomenon.

In astronomy, then, and in much of what the Greeks called 'meteorology', we are at liberty to suggest that the early theorists were often uncritical, or that they seriously underestimated the complexity of the phenomena; but where experiment is impossible for objective, physical reasons, the criticism that they failed to use the experimental

I Mere. $342 a, 3$ ff., cf. $344 a, 25 \mathrm{ff}$. on comets.

2 Mete. $369 b, 8 \mathrm{ff}$. The expression that sight mротерEiv rĩs ónoñs might be thought rather odd in view of the fact that elsewhere Aristotle flatly denies (against the opinion of Empedocles) that light travels at all (e.g. Sens. $446 a, 25$ ff., $b, 27$ f.).

3 Mere. $374 b, 3 \mathrm{ff}$. He refers, also, to the rainbows formed under certain conditions when an oar is raised out of the water $(374 a, 29 \mathrm{ff}$.).

4 This was first achieved by Newton in his Opticks (1704), following on the work of Descartes and Marci. 
method is, clearly, wide of the mark. But we have now to deal with the more interesting and more difficult problems of the role of experiment in other fields, and first of all in the sciences we know as physics and chemistry. First physics, and I may begin by considering briefly those departments of physics, such as optics, acoustics, statics and hydrostatics, in which the achievements of Greek science are by no means negligible. Concerning the Greek contribution to the study of optics, in particular, we have comparatively good information, since there are several treatises extant either in the original or in Latin translations which are specially devoted to the subject, the most important being Euclid's Optics, the De Speculis (presumed to be a digest of the Catoptrics of Hero of Alexandria) and a Latin translation of an Arabic version of another Greek treatise on optics which there is no good reason to doubt is the work of Ptolemy. 'These works make it abundantly clear not only that the Greeks were successful in their application of geometry to the study of reflection and refraction, but also that some investigators undertook quite extensive experiments to corroborate the principles of optics which they formulated. Some passages from Ptolemy's Optics are worth quoting to illustrate one investigator's methods. At the beginning of Book III (ch. 3,88 , $9 \mathrm{ff}$. Lejeune) the writer sets out three elementary principles or laws of reflection. These are ( 1 ) that objects that are seen in mirrors are seen in the direction of the visual ray which falls on them when reflected by the mirror; (2) that things that are seen in mirrors are seen on the perpendicular which falls from the object to the surface of the mirror and is produced; and (3) the position of the reflected ray, from the eye to the mirror and from the mirror to the object, is such that each of its two parts contains the point of reflection and makes equal angles with the perpendicular to the mirror at that point. ${ }^{2}$ The truth of these principles, he goes on, is confirmed by the phenomena, and he proceeds to cite a series of simple experiments to corroborate his laws. Thus to confirm his first principle he remarks (III, ch. 4, 89, 5 ff.): 'in the case of all mirrors (that is plane, convex and concave) we find that if we mark the points on the surface through which the images are seen, and cover these points, then the image of the object will certainly no longer be visible. But then when we uncover the points one by one and look at the uncovered points, both the points and the image of the object will be seen together on the straight line drawn to the summit of the visual ray (i.e. the eye).' Further experiments follow: one which is particularly remarkable involves the use of three mirrors, one plane, one convex and one concave,

"This is the conclusion of the most recent editor, A. Lejeune, L'Optique de Cloude Ptolemée (Louvain, 1956), Introduction, Pp. 13-26.

"With reference to the diagram where $M R$ is the mirror, $A$ the eye, $B$ the object, $B^{\prime}$ the image, $O$ the point at which the visual ray strikes the mirror, and $T O$ and $B P$ perpendiculars to the mirror, these three principles are: (1) $B^{\prime}$ lies on $A O$ produced, (2) $B^{\prime}$ lies on $B P$ produced, (3) $\angle T O A=\angle T O B$. (After Cohen and Drabkin, A Source Book in Greek Science, New York, 1948, p. 269, n. I.)

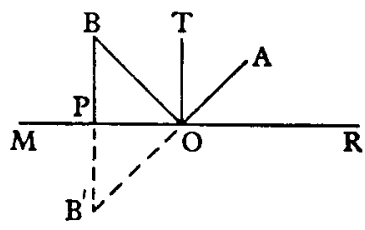


and confirms very neatly that the angle of incidence is equal to the angle of reflection in each case.

These are simple, but generally very effective, tests undertaken to corroborate the elementary laws of reflection, but elsewhere the author carries out experiments of a greater complexity, notably in his discussion of refraction in Book v. There (v, ch. 3,224 , roff.) he first points out that as in reflection, so too in refraction, the image is seen at the intersection of the line of the visual ray and the perpendicular drawn from the object to the reflecting or refracting surface, and here he refers to an experiment which goes back at least as far as Archimedes, ${ }^{\mathrm{I}}$ in which a coin is put into an opaque vessel in such a position that it is just hidden by the lip of the vessel, but comes into view when water is poured into the vessel. But not content merely to state certain general principles of refraction, he undertakes detailed investigations to measure the amount of refraction which takes place at different angles of incidence, and in different media. First (v, ch. 7, 227, Iff.) he describes the setting up of his apparatus. To measure the angles he uses a circular disk, each quadrant of which is divided into ninety parts (i.e. like a protractor): this disk is set up in a bowl of clean water so that the water just covers the bottom half of the circle. He then describes how a coloured marker is to be placed at different points along the circumference of one or other of the two quadrants which are above the water level, and how sightings are to be taken so that the coloured marker and the centre of the disk are aligned with the eye. The next operation is to move a small, thin rod along the circumference of the opposite quadrant which is under the water until the extremity of the rod appears in line with the coloured marker and the centre of the disk. This enables one to determine both the angle of incidence and the angle of refraction, and when these are measured, we find that the angle of incidence is always greater than the angle of refraction, and that as the angle of incidence increases the amount of refraction becomes progressively greater. The results obtained by Ptolemy are given in detail: when the angle of incidence is ro degrees, the angle of refraction will be about 8 degrees; when the angle of incidence is 20 degrees, the angle of refraction will be $15 \frac{1}{2}$ degrees, and so on for angles of incidence up to 80 degrees. Concluding the passage with the remark that 'this is the method by which we have discovered the amount of refraction in the case of water', Ptolemy adds the note: 'we have found no perceptible difference in this respect between waters of different densities or rarities' (ch. 12, 230, $4 \mathrm{ff}$.). It is worth drawing attention to the point that Ptolemy evidently tried the same experiment with different kinds of waters to see whether this gave different results, and elsewhere in the Optics we find set out in detail the results of his investigations of the refraction of other media, namely from arr to glass and from water to glass. ${ }^{2}$

In investigating the problems of reflection and refraction Ptolemy carried out extensive experiments to corroborate his general laws and in particular to establish that there is a definite quantitative relationship between the angle of incidence and the

See Lejeune, op. cit. n. 9 to $225,9$.

${ }^{2}$ It should be noted that Ptolemy considers the ray from the eye, not that from the object, the incident ray. For his results, which are expressed to within half a degree, compare the tables given by Brunet and Mieli, Histoire des sciences: Antiquité (Paris, 1935), Pp. $825 \mathrm{ff}$. 
angle of refraction. Both the problems in question, and the experiments used to study them, are, of course, quite elementary. But I have chosen this example deliberately in order to indicate that where the circumstances were favourable, that is where the problems are relatively simple and where they could be investigated empirically without too great difficulty, we do find evidence that detailed experiments were sometimes carried out in antiquity. But is this the case, perhaps, only in quite late antiquity? Are we to consider the experiments of a Ptolemy in optics, or of a Philo or a Hero in pneumatics, as quite exceptional, as marking, in fact, a radical break with the methods of investigation used in earlier periods? Or is what distinguishes Ptolemy from earlier writers on optics merely the success or thoroughness with which he applied techniques of investigation which had been used, though not fully exploited, before? Without entering into the various problems raised by the development of each one of the branches of physics in antiquity, I may briefly consider the question in so far as it concerns the earliest period of Greek science, for poor though our information is, there are grounds for believing that some problems of physics had already begun to be investigated with the help of simple tests in the Presocratic period or in the early fourth century. Some of this evidence is well known. We are all acquainted with the legends that purport to describe the experiments which led Pythagoras to discover the numerical relations between the musical intervals of the octave, fifth and fourth. One story has it that he made this discovery by measuring the weights of hammers which made different notes when struck, another that he did so as a result of experiments in which he attached different weights to a string and observed a relationship between tension and pitch, a third that he filled jars with varying amounts of water and noted a relation between the quantity of water and the sounds the jar made when struck, a fourth that he measured the lengths of string or pipe which gave various notes. These accounts, as is well known, contain much that is pure fantasy : ${ }^{\mathbf{I}}$ in the majority of cases when the test is carried out in the manner described in our sources, it does not, in fact, reveal the simple relations between the various musical intervals. Nevertheless we.should not dismiss these stories as entirely worthless, for all their obvious inaccuracies. For one thing the very fact that such legends circulated about this discovery in antiquity suggests some recognition (if only a theoretical recognition) of the value of the experimental method, for example in determining which are the causative factors governing a particular effect. ${ }^{2}$ Secondly, if most of these supposed tests do not, in fact, yield the results reported, exceptions must be made of two of the investigations referred to, those with the monochord and with the columns of air in pipes, for here, of course, other things being equal (e.g. the thickness, material and tension of the string) the relations between the musical intervals are readily determined with reference to the lengths of the string or pipe. We have other evidence, too,

\footnotetext{
I See, for example, Guthrie, A History of Greek Philosophy, vol. I (Cambridge, 1962), pp. 220 ff., esp. $223 \mathrm{ff}$., who gives the Greek sources and comments on the various difficulties which these stories contain. Guthrie concludes that if the discovery of the relations between the intervals is indeed Pythagoras', it was no doubt on the monochord that he carried out his experiments.

${ }^{2}$ Cf. the judgement of Zubov, op. cit. p. 224: 'Allein die Tatsache, da $B$ eine solche Legende in der Antike auf kam, zeugt von dem Verständnis des Wesens des Experimentes als einer rationalen Untersuchung der Wirklichkeit.'
} 
besides the stories which refer to Pythagoras himself, which tends to confirm that the early Pythagoreans carried out certain empirical investigations in acoustics. There is the interesting, though admittedly obscure, report that Hippasus constructed bronze disks of varying thicknesses to produce certain harmonies, ${ }^{\mathbf{}}$ and in a fragment preserved by Porphyry, Archytas refers to a variety of phenomena in an attempt to establish his theory relating the pitch of a note to its 'speed', and some of the evidence he cited seems to derive from first-hand investigations (e.g. the variations in the pitch of the sound produced when a stick is moved at different speeds, and the notes produced by different lengths of pipe): ${ }^{2}$ Finally it is worth recalling that Plato too provides evidence of early empirical investigations in acoustics, for in the Republic Socrates is made to refer (with disapproval) to those who 'measure the harmonies and sounds they hear against one another' (53 I A, I ff.) and who 'look for numbers in these heard harmonies' ( $c, \mathrm{I} f$.).

Acoustics, then, is one field in which the Greeks both observed and conducted rudimentary empirical tests from a very early period, and the same may be said of pneumatics and of what was later to become (with Archimedes) the science of hydrostatics. Beginning with Empedocles and Anaxagoras we find a whole series of Greek theorists who investigated the phenomena of air pressure by observing the behaviour of air enclosed in the clepsydra and other vessels, both repeating and modifying the simple experience described by Empedocles himself (fr. 100). The author of the pseudo-Aristotelian Problemata, for example, objects against Anaxagoras that it is not enough simply to say that air is the cause of the water not entering the bulb of the clepsydra when the tube at the top is blocked, for in some circumstances, viz. when the clepsydra is immersed obliquely in the water, this does not happen $(914 b, 9 \mathrm{ff}$.). In the Hippocratic Corpus there are several texts which refer to simple investigations of air and water pressure, as for example the creation of what we should call a partial vacuum by inverting a narrow-necked vessel containing water or oil, and the release of the vacuum by piercing a hole in the vessel. 3 But two rather more elaborate tests are worth mentioning particularly. One writer describes a test which demonstrates that water finds its own level: this involves setting up an apparatus of three or more intercommunicating vessels on level ground (this point is stressed), and the writer describes how the whole system may be filled or emptied by filling or emptying any one of the vessels (though he then uses this piece of information to support a highly speculative theory of the interplay of the humours in the body).4

I A scholium on Plato, Phaedo $108 \mathrm{D}$ (DK, I8 8 12) contains a report of Aristoxenus which refers to Hippasus' construction, and it seems possible that this may have been designed (as Burnet suggested in a note in his ed. of the Phaedo ad loc.) to provide a model to illustrate the harmony of the spheres.

${ }^{2}$ Fr. 1. The significance of this fragment for our understanding of the role of experiment in Presocratic, particularly Pythagorean, philosophy, has been discussed by G. Senn, 'Uber Herkunft und Stil der Beschreibungen von Experimenten im Corpus Hippocraticum', Arch. f. Gesch. d. Medizin, Xxil (1929), pp. 271 ff.

3 On Diseases, 1v, ch. 57, L. vil, 612, 6ff. (on which see Senn, op. cit. pp. $248 \mathrm{ff}$.) and ch. 51, 588, $17 \mathrm{ff}$. Cf. also On the Nature of the Child, ch. 18, 502, 2 f., and ch. 25, 522, $20 \mathrm{ff}$. (on which see Senn, pp. $245 \mathrm{ff}$.).

4 On Diseases, Iv, ch. 39, L. vil, 556, 17 ff., on which Senn commented (op. cit. p. 232): 'wieder eine anschauliche Beschreibung eines einwandfrei durchgeführten physikalischen Experiments'. 
And another quite ambitious test is described in the treatise On the Nature of the Child (ch. 17, L. vil, 498, 17 ff.). This involves putting three different substances (earth, sand and lead-filings) into a bladder full of water and agitating them by blowing on them through a tube let down into the vessel. The author refers to this test to support his theory that the various parts of the body are formed by the action of like coming to like, but it seems probable that this test was originally designed not to illustrate the action of like-to-like, but to study the reactions of substances of different specific gravities in partial suspension in water, and that the author of On the Nature of the Child attempted to adapt this experiment to suit his own purposes. ${ }^{\text {I }}$

Further examples of simple physical experiments might be mentioned not only from the Hippocratic Corpus but also from Aristotle, ${ }^{2}$ but it is apparent from those we have considered that in some branches of physics, where the problems are fairly elementary and where tests could be carried out without any great difficulty, certain rudimentary experiments were conducted even as early as the fifth or the fourth century B.C., even if these are neither so precise nor so complex as those conducted later by Philo and Hero in pneumatics, for instance, or by Ptolemy in optics. In some fields, then, there is a definite (if only a quite slow) progress, in antiquity, in the application of experimental methods to the study of certain physical phenomena, and in some cases the beginnings of this development can be traced already in the Presocratic period or shortly afterwards. But is it not the case that in dynamics, at least, the efforts of the earliest Greek scientists, and indeed of Greek scientists as a whole, were quite vitiated by their failure to experiment? It is all very well, I shall be told, to point to a few exceptional cases where the Greeks did conduct some simple tests, but the significance of these pales by comparison with the manifest failure to investigate the problems of motion experimentally. Can we deny that the main reason why Aristotle in particular failed to formulate adequate laws of motion, and why Galileo was so much more successful in this field, was simply this, that the first quite ignored the experimental method, while the second was indefatigable in devising and conducting practical tests to corroborate his theories? To assess how much truth there is in these judgements, we should first consider the early history of dynamics and the relation between Aristotle's theory of motion and earlier views. It is hardly an exaggeration to say that before Aristotle himself there is nothing that can be called dynamics at all in Greek science. The Presocratics refer in various contexts to the attraction of like things to one another, but this generalization embraces a very wide range of phenomena. The

'Senn, op. cit. pp. $242 \mathrm{ff}$, concludes that the test described was probably in origin a 'Sedimentierungsversuch', which the Hippocratic author applied to support his theory of the action of the 'breath' causing like substances to come together in the developing embryo.

2 Perhaps the best known example in the Hippocratic Corpus is the test described in On Airs, Waters, Places, ch. 8, CMG, 1, 1, 63, $12 \mathrm{ff}$., in which a bowl of water is left out of doors to freeze and when the water is thawed it is found on being remeasured to be less than the original quantity (a test which the writer supposes supports his contention that freezing causes the "lightest and finest' part of the water to be dried up and disappear). In Aristotle we find, for example, two references to the fact that if a vessel is heated and then inverted over water, as the air in the vessel cools it contracts and some of the water is drawn up into the vessel, though it may be thought unlikely that Aristotle himself originated this test (Cael. $312 b, 13 \mathrm{ff}$; $G A, 739 b$, roff, reading kwvikơ with Platt, for ókóvita). 
action of gravitational forces may be included under this heading, but so too may the behaviour of animals: in a fragment quoted by Sextus Empiricus, Democritus refers explicitly to both animate and inanimate examples to illustrate how like is drawn to, and known by, like, that is on the one hand to certain gregarious species of animals (pigeons and cranes are mentioned in particular) and on the other to the separation of seeds according to their kinds in a winnowing-basket, and to that of pebbles according to their different shapes on the sea-shore. ${ }^{I}$ It is Aristotle himself, then, who makes the first serious attempt to formulate general theories in dynamics in which the relevant factors governing the velocity of a moving object are interrelated. In various passages in the Physics and the de Caelo he isolates two main factors which govern the speed of a moving object, namely its weight (which in the case of objects of the same kind varies directly with the size) and the 'density' of the medium. ${ }^{2}$ And he puts forward theories concerning the relation between these factors and velocity in 'natural', and in 'forced', motion. Thus in natural motion, that is in the case of freely falling or freely rising bodies, velocity is said to be directly proportional to the weight of the body and inversely proportional to the density of the medium, while in forced motion velocity is said to be directly proportional to the force applied and inversely proportional to the mass of the body moved $^{3}$ (and Aristotle also suggests that whereas in natural motion the speed of the object increases the nearer it comes to its "natural place', in forced motion the velocity decreases as the object progresses further away from the propelling agent ${ }^{4}$ ).

These, the main theories of Aristotelian dynamics, represent, then, the first attempt to formulate abstract 'laws' of motion, to establish the relation between the various factors which determine the speed of moving objects, while discounting irrelevant considerations. Aristotle assumes, for example, that the medium is completely homogeneous, although it is never so in fact, 5 and while he notes that the speed of an object is influenced by its shape, he leaves this too out of account when proposing his general doctrines of natural and forced motion. But then the next point that should be made is that the theories he suggests correspond to observed phenomena much more closely than might at first sight seem likely in view of the discrepancy between Aristotelian and Newtonian dynamics. Aristotle has often been taken to task for assuming that the velocity of a freely falling body varies directly with its weight, but it is as well to be clear where his mistake lies. The fact is that in air heavier bodies do fall more rapidly than lighter ones of the same shape and size (though this is not true, of course, in a vacuum). Aristotle was correct in assuming that there is some

${ }^{1}$ Sext. Adv. math. vil, 117 (DK, 68 B 164), cf. also Aet. 1v, 19, 13 (DK, A 128). Plato uses a similar model to illustrate the separation of like to like in the Receptacle at $T i .52 \mathrm{E}-53 \mathrm{~A}$.

${ }^{2} \mathrm{He}$ also notes, e.g. at Cael. $313 \mathrm{a}$, $14 \mathrm{ff}$., that the speed of an object is influenced by its shape.

${ }^{3}$ E.g. Cael. $273 b, 30 \mathrm{ff}$; $277 b,{ }_{3}$ ff.; Ph. $215 a, 25 \mathrm{ff}$. (on natural motion) and $P h .249 b, 27 \mathrm{ff}$. (on forced motion).

4 Ph. $230 b, 24 \mathrm{ff}$. and Cael. $277 a, 27 \mathrm{ff}$. At Cael. $288 a$, $19 \mathrm{ff}$. it is suggested that in some cases the highest speed is attained not at the point from which flight begins nor where it ends but óvò uÉoov, but if this means what it appears to mean, namely that the highest speed is attained in the middle of the flight, it is hardly possible to interpret it consistently with Aristotle's known doctrines. See the notes of Stocks in the Oxford Translation and of Guthrie in the Loeb edition of the de Ceelo.

s See Cohen and Drabkin, op. cit. p. 203, n. $x$. 
relationship between weight and velocity in motion that takes place in a medium, although the relationship is not a simple one of direct proportion. Then too it is an obvious fact of experience that motion through a dense medium is slower than through a rare one, but again Aristotle's theory oversimplifies the relationship between the density of the medium and velocity. Moreover the consequences of this were especially unfortunate, for it led him to deny that motion through a void is possible (the velocity would be infinitely great), ${ }^{\mathbf{I}}$ and here the contrast between Aristotelian and modern dynamics is most pointed, for while we should say that the effects of the resistance of the medium should be discounted in considering the relationship between force, mass and velocity, Aristotle assumes throughout his discussion that motion must take place through a medium.

The 'laws' of motion which Aristotle proposes are not utterly at variance with experience: rather they are hasty generalizations based on superficial observations. His discussion of the problems of motion in the Physics and de Caelo is highly theoretical (it is not often that he explicitly refers to empirical evidence in this connection at all), but even so it is at least arguable that in assuming that motion necessarily takes place through a medium, he stayed too close, rather than not close enough, to the data of experience. Yet this does not alter the fact that he quite failed to verify his theories experimentally, for if empirical evidence is only seldom referred to in this context in the Physics and de Caelo, experiments, whether his own or those of his predecessors or contemporaries, are mentioned even more rarely. ${ }^{2}$ Furthermore, nothing precluded the carrying out of certain simple tests which would have indicated the falsity of his general theories of natural and forced motion (even if they would not necessarily have suggested a better alternative account). In the Discorsi, published in 1638 , Galileo describes in detail his experiments with a pendulum and with an inclined plane (down which he rolled bronze balls) and he also refers to the more famous experiment of dropping balls of different weights from a considerable height (though several scholars doubt Viviani's report that he carried out this experiment from the Leaning Tower of Pisa). None of these tests was beyond the range of what was technically possible for the ancient Greeks, ${ }^{3}$ and any of them might have been used to

'Ph. $\Delta$, ch. 8, esp. $215 a, 24$ ff.; $216 a$, irff.

${ }^{2}$ A notable exception is the passage at $C_{a} l .311 b, 9 \mathrm{ff}$., where he says that each of the elements, except fire, has weight in its own 'natural place' and adduces as proof of this that a bladder weighs more when inflated than when empty. This experiment has been sharply criticized, e.g. by Ross, Introduction to his ed. of the Physics, pp. $26 \mathrm{ff}$., on the grounds ( 1 ) that the supposed experimental fact is not correct, and (2) that Aristotle's theory is not true to the experimental facts he thought he had at his command. But whether or not a bladder will weigh more when inflated will depend on, among other things, (1) whether it is inflated with atmospheric air or with breath (which contains a higher proportion of carbon dioxide), (2) whether it is inflated under pressure or not, and (3) the amount of water vapour in the gas with which it is filled. At least three different attempts were made to carry out this test in antiquity (by Aristotle, by Ptolemy and by Simplicius, see Simp. in Cael. $710,24 \mathrm{ff}$. and cf. also Anon. Lond. xxxı, 33 ff.), but that three different results were obtained is, perhaps, hardly surprising, considering the lack of precise weighing instruments and the number of factors which might influence the outcome of the test.

3 The Greeks had no precise means of measuring time, but no more had Galileo. In the Discorsi he describes the method he employed for measuring time in his dynamical experiments, namely that of weighing the amounts of water which percolated through a thin jet, a simple adaptation of the principle of the water-clock. 
demonstrate the inadequacies of Aristotelian dynamics (and in particular the doctrine that in natural motion velocity is directly proportional to weight). Here, then, it seems that we have a clear case in which the earlier Greek investigators might have carried out certain tests in conjunction with their theories, but quite failed to do so; but if this judgement is true in the main, two reservations should be added. First we must repeat that what Galileo understood, but Aristotle failed to appreciate and indeed would have denied, was that in studying the conditions of uniform or accelerated motion, the effects of friction and of the resistance of the medium should be discounted. Thus while it was certainly open to Aristotle to perform the three types of experiment I have mentioned, yet so long as the necessary corrections were not made to offset the effects of friction and air resistance, the actual results obtained from such experiments would certainly be difficult to interpret and perhaps even positively misleading. Second, and more important, while it is undoubtedly the case that Aristotle himself failed, in general, to undertake practical tests in connection with his theory of motion, this is much less true of some of his successors. Some of the examples of objects in motion which are discussed in the Problemata appear to derive less from common experience than from deliberate investigations, ${ }^{\mathbf{I}}$ and Strato too carried out certain tests in this field, for example to establish the fact that falling bodies undergo acceleration. ${ }^{2}$ Such empirical investigations as are recorded are all quite rudimentary (Strato apparently observed the impact made by stones dropped from different heights, and the way in which when water falls from a considerable height, its flow is continuous at the top, but broken at the bottom of its fall), but they may be taken to indicate that the possibility of carrying out practical tests to illuminate the problems of dynamics was not wholly ignored by Aristotle's immediate successors. Nor should we fail to note that this method was used with much greater success in later antiquity. Philoponus, for example, challenged the fundamental assumptions of Aristotelian dynamics on both theoretical and empirical grounds. Arguing against the doctrine that the speed of a falling body is proportional to its weight, he says 'but this is completely false. And this may be confirmed more forcibly by actual observation than by any sort of verbal demonstration', and he then proceeds to adduce (as a thousand years later Galileo was to adduce) the evidence of what happens when you drop two different weights from the same height: 'you will see that the ratio of the times required for the motion does not depend on the ratio of the weights, but that the difference in time is a very small one.' 3

The next field we must discuss is chemistry, or rather what passes for chemistry in antiquity, that is, the study of the constituent elements of substances and their

I E.g. the account of objects rebounding from a plane, and that of the figures described by certain solids, namely the cylinder and the cone, when these are revolved (Probl. xv1, 4 and 13 , $913 b, 6 \mathrm{ff}$. and $9156,18 \mathrm{ff}$., and xvi, $5,913 b, 37 \mathrm{ff}$ ). A passage in the Mechanics $(858 a, 13 \mathrm{ff}$.) is worth quoting as it illustrates the difficulty which the writer experienced in tackling the problem of 'why objects which are hurled come to a standstill'. 'Does it stop when the force which started it fails, or because the object is drawn in a contrary direction, or is it due to its downward tendency, which is stronger than the force which threw it? Or is it absurd to discuss such questions while the

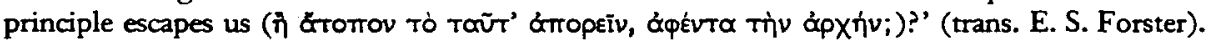

2 See Simplicius, in Ph. 916, 1off. (Wehrli, Straton von Lampsakos, fr. 73).

3 Philoponus, in $P h .683,16 \mathrm{ff}$. 
interactions. Here the Presocratics made several very important contributions, though nearly all of them relate to the conceptual framework of 'chemical' theory, rather than to the discovery of facts. Thus it was one of Empedocles' most striking achievements that he explained how a variety of different substances may be derived from a limited number of primary elements by suggesting that the elements combine with one another in different proportions: : $^{\mathrm{s}}$ something like the modern 'law of fixed proportions', which states that chemical compounds always contain their constituent elements in fixed and invariable proportions by weight, was in fact assumed long before it could be demonstrated experimentally. Aristotle, in turn, succeeded, for example, in distinguishing various modes of mixture and combination, including oiverols (i.e. an aggregation of different substances in what we should term a mechanical mixture, for example a pile of barley and wheat grains) and $\mu i \xi i s$ (in which the component substances are fused and the resulting compound acquires new properties, for example when tin and copper combine to form bronze-though it should be noted

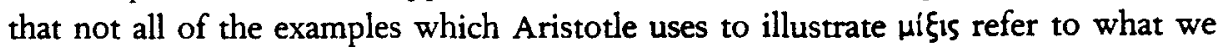
should class as chemical compounds). ${ }^{2}$ But then one asks, how far is it the case that early Greek theories concerning the constituent elements of things were merely a series of conjectures which they never attempted to verify or falsify by means of experimental investigations? Now as in the early history of dynamics, so too in the development of theories about the constituent elements of things, attempts were made to formulate systematic general theories before much empirical research had been undertaken. But by the time of Aristotle or shortly afterwards detailed empirical investigations had begun to be carried out in this field. Aristotle's discussion of the nature and number of the elements in the de Generatione et Corruptione is largely dogmatic, ${ }^{3}$ but if we turn to the Meteorologica, the extent of the knowledge which it displays concerning the reactions of different substances to various simple tests is remarkable.4 It is true that Aristotle tends to present his results in the form of generalizations, for example "of things which are solidified by heat or cold, those that are soluble are dissolved by their opposites. For those that are solidified by dry heat

' See frr. 96 and 98 on the formula or composition of bone, blood and 'other forms of fiesh'.

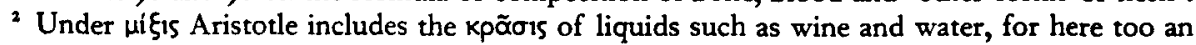
interaction may take place and the resultant compound may be opotouspris ( $G C, \mathrm{~A}$, ch. 10, esp. $328 a, 26 \mathrm{ff}$. and $b, 3 \mathrm{ff}$.). On Aristotle's theory of different types of mixture and combination, see esp. H. H. Joachim, Journal of Philology, xxix (1904), pp. 72 ff.

${ }_{3}$ Thus in $G C, \mathrm{~B}$, chs. I ff. when he sets out to determine the nature and number of the elements, he argues (I) that coming to be and passing away are impossible without perceptible bodies $(328 b, 32 \mathrm{f}$.), which in turn cannot exist apart from contrarieties; for a body must be either heavy or light, either hot or cold ( $329 a$, roff.), (2) that the principles of perceptible body will be tangible contrarieties $(329 b, 7 f f$.$) , and (3) that the tangible contrarieties may be reduced to two pairs of$ opposites, hot and cold, and wet and dry, but these cannot be resolved any further $(329 b, 24 \mathrm{ff}$; $330 a, 24 \mathrm{ff}$.).

4 For the purposes of this paper I shall include the fourth book of the Meteorologica as this is clearly evidence for the work of Aristotle's immediate school, even if some have denied that it is an authentic text of Aristotle himself (e.g. Hammer-Jensen, Hermes, L (1915), pp. 113 ff., and Gottschalk, CQ, n.s: xI (1961), pp. 67 ff., and contrast Düring, Aristotle's Chemical Treatise, Meteorologica, Book IV (Göteborg, 1944), pp. I7ff. and Lee, Introduction to the Loeb edition, pp. xiii ff. and Preface to the second edition, 1962, p. vii, who have argued that there are no good reasons for not accepting the book as a whole, or in the main, as the work of Aristotle). 
are dissolved by water (which is wet and cold) and those that are solidified by cold are dissolved by fire' (Mete. $\Delta, 382 b, 33$ ff.). But much detailed knowledge underlies these generalizations. Aristotle evidently collected a good deal of information concerning the physical properties of a wide variety of substances (i.e. which substances are ductile, which malleable, which fissile and so on) and also concerning their reactions to fire and to water, to being burned, boiled or dissolved in various types of liquid. Much of what is contained in Meteorologica $\Delta$ was no doubt common knowledge. Some of his more specialized information comes from an acquaintance with such contemporary industrial processes as iron-making. But some of his knowledge clearly derives from deliberate investigations (whether or not it was Aristotle himself who originally undertook these). Thus he says that salt and soda are soluble in some liquids, such as water, but not in others (he specifies olive oil, Mete. $3836,13 \mathrm{ff}$.). Among the substances which he says freeze solid with cold are not only urine, vinegar, whey and lye (Kovía, the alkaline solution used as a detergent), but also

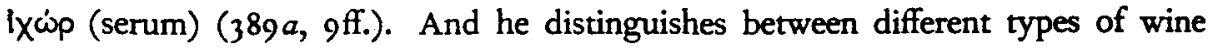
according to their combustibility and their readiness to freeze $(387 b, 9 \mathrm{ff}$; $388 a$, 33 ff.).

Sometimes, indeed, Aristotle explicitly claims to have discovered or proved something by a practical test, although the experiments which he does describe in the Meteorologica have often been severely criticized by modern scholars. ${ }^{2}$ In one case these criticisms are probably quite justified. At $358 b, 34 \mathrm{ff}$., when he wishes to show that the salmess of the sea is due to an admixture, he describes an experiment in which a wax jar is let down into the sea with its top securely fastened, and he says that when the jar is recovered, fresh water will be found to have percolated through the wax walls. ${ }^{3}$ But, as many scholars have pointed out, this does not, in fact, occur, and they have concluded that Aristotle never undertook this experiment himself but is simply repeating the story on hearsay. This is, no doubt, the most probable explanation, and yet it seems just possible that he did carry out the test, and that he found a small quantity of fresh water inside the jar which was the result of the condensation of water vapour which the jar had contained before it was let down into the sea (though this would not, of course, alter the fact that his theory as to how the water came to be there is quite incorrect). Another passage in which he claims to have carried out some experiments occurs in the same chapter at $3586,16 \mathrm{ff}$. 'We have proved by experiment

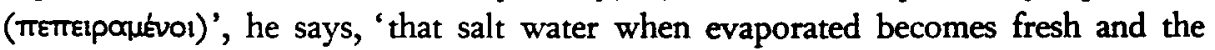
vapour does not form sea water when it condenses again.' So far so good, and Aristotle clearly deserves full marks both for the method he used and the results he obtained. But he then goes on: 'and the same is true in other cases. For wine and all other Xupol (flavoured liquids) that evaporate and condense into liquid again, become water.' But it is far from being the case, as editors of the Meteorologica and others have pointed out, that when wine is evaporated in a still it becomes water, and Lee,

'See Mete. $383 a, 32 \mathrm{ff}$. (with Lee's useful note) and cf. $383 a, 24$ f. on the manufacture of pottery and $3836,7 \mathrm{ff}$. on that of millstones.

${ }^{2}$ E.g. H. Diels, Hermes, xx (1905), pp. $310 f$.

${ }^{3}$ Cf. $H A, 590 a, 24$ ff. Aristotle's statement was apparently accepted on trust by Pliny (xxxI, 37) and by Aelian (1x, 64). 
for one, concludes that 'Aristotle had apparently only performed the experiment with water'. But in this instance, too, another explanation is possible, and even, I think, more likely. It is commonly assumed, I believe, that if Aristotle tried these experiments at all, he used some sort of still or condenser, but I wonder whether this was the case. The vapour driven off a boiling liquid could be collected in small quantities on any cold flat surface held directly over the vessel (the author of the Hippocratic treatise On Breaths refers to the phenomenon in question and uses it to suggest an account of how sweat is formed ${ }^{1}$ ) and it should also be noted that the most primitive method of distillation employed in antiquity seems to have made no use of a condenser, the vapour being collected in an absorbent material (such as wool) which was held over the boiling liquid. ${ }^{2}$ But if wine is evaporated and the vapour collected on a plate or some such object held over the boiling wine, the liquid which condenses is a colourless, almost flavourless fluid of low alcoholic content which would pass for 'water' as naturally as the liquid collected from evaporating sea-water. To my mind, then, it seems probable enough that this is what Aristotle is referring to when he says that 'wine and flavoured liquids' become water, and we should not necessarily conclude that he is simply repeating something on hearsay. 3

The Meteorologica itself is the first extant work which deals in any great detail with the properties of different substances or their reactions to certain simple tests, ${ }^{4}$ but thereafter Aristotle's work in this field was followed up and extended by other investigators. Theophrastus' book On Stones, in particular, is an important collection of data concerning the properties and kinds of mineral substances, and On Fire contains a quite detailed discussion concerning the species of fire and the effects of different forms of heat. It appears, indeed, that in the latter part of the fourth century certain inquiries were undertaken in the field we should call chemistry which were parallel to, though less intensive than, the researches carried out in zoology and botany. But why, then, one may ask, did these investigations into the properties of substances not lead to any radical advance in doctrine, or at least to the overthrow of the four-element theory of Aristotle? Now the fact is that the research that was done did lead both to an increase of factual knowledge and to the suggestion of certain modifications in the Aristotelian doctrine. Aristotle himself conceded that his method of classifying compounds according to whether earth or water predominated in them left certain problems which he found difficult to resolve.5 But then the work of Theophrastus raised two major difficulties: first there was his detailed analysis of different types of

I Flat. ch. 8; CMG, 1, 1, 96, I5ff.

2 This method of distillation is described in Dioscorides, de Mat. Med. 1, 72, 3 .

${ }^{3}$ It may be noted that elsewhere in Mete. $\Delta$ different sorts of wine are distinguished according to their reactions to being heated or frozen: new wine, for example, is said to thicken most under the influence of heat and to solidify least under the influence of cold $(388 a, 33 \mathrm{ff}$; cf. also $384 a$, 4 ff. and 3876 , 9 ff.).

4 Mete. $\Delta$ does, however, owe a good deal to Plato's Timaeus, particularly to the account of the varieries of water and of earth and of their compounds, $58 \mathrm{D}-6 \mathrm{r} \mathrm{C}$.

5 In general, Aristotle considers most compounds to be composed of water and earth (those that are solidified by cold and melted by fire are said to have a greater proportion of water, those that are solidified by heat to contain more earth), but olive oil and semen, in particular, both present difficulties which he attempts to resolve by suggesting that these are compounds of water

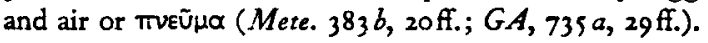


'earth' (On Stones, chs. 48ff., especially) which implicitly raised the problem of the basic nature of this 'simple body', and then in On Fire (chs. Iff.) he explicitly raised the question of the nature of fire and drew attention to certain important respects in which it differs from the other 'simple bodies' (notably in that it always exists in a substrate). If the four-element theory as a whole survived these and other challenges in antiquity, this was due to a complex of reasons, partly no doubt because the methods of investigation used were still fairly rudimentary (in particular insufficient use was made of quantitative measurements, even though the Greeks were accustomed to distinguish different types of waters, and indeed also different solids, by their weight ${ }^{\mathrm{I}}$ ), but partly also because of the nature of the four-element theory itself: this provided at once an extremely comprehensive, and a quite imprecise, theory embracing each of the different states of matter, solid, liquid and gaseous, so that the effect of much of the research that was undertaken was to modify the application of the theory in detail rather than to show that a more adequate general theory was needed. ${ }^{2}$

So far I have dealt entirely with the physical sciences, bearing in mind that it is to these that reference is usually made to substantiate the view that there is a radical difference in method and outlook between ancient and modern science. My remarks on biology and medicine must be even more compressed than my discussion has been so far. In the biological sciences, the key method of research, from Alcmaeon onwards, was dissection, including not only the dissection of dead adult animals, but also (as time went on) the dissection of embryos and vivisection. ${ }^{3}$ Now dissection is always an experimental procedure in the weak sense in that it involves not simply direct observation, but 'observations provoquées', that is, a piece of research deliberately undertaken to discover facts. But sometimes we find dissections used not merely to uncover facts but to prove or disprove suggested theories. At $G A, 764 a$, $33 \mathrm{ff}$., Aristotle is able to refute the doctrine which we find expressed in various forms in earlier writers, that the sex of the embryo is determined by the side of the womb on which it is conceived. 'Male and female twins are often found together in the same part of the uterus', he says. 'This we have observed sufficiently by dissection in all the Vivipara, both land-animals and fish.' 4 And in another passage ( $G A, 746 a$, 19ff.) he again refers to the evidence of dissections to disprove the notion that the

1 The author of $O$ n Airs, Waters, Places (ch. 1, CMG, 1, 1, $56,7 \mathrm{ff}$.) for example, notes that

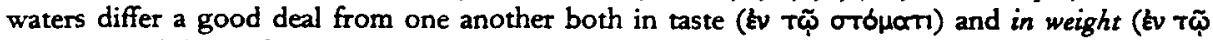
$\sigma \tau 0 \theta \mu(\tilde{)})$, while in $O_{n}$ Stones (chs. 22 and 39) Theophrastus refers to differences in 'density"

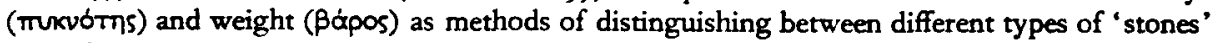
(including, e.g., ores).

2 I have dealt solely with the four-element theory. But it may be noted that its main rival in the fourth century, the atomistic theory, was equally comprehensive and vague, and equally incapable of being corroborated or falsified by means of practical tests.

3 The history of the use of dissection in antiquity has been described by L. Edelstein, 'Die Geschichte der Sektion in der Antike', Quell. u. Stud. z. Gesch. der Naturwissenschaften u. der Medizin, III (1933), pp. rooff.

4 At $G A, 765 a, 21 \mathrm{ff}$., Aristotle refers to those who held that the sex of the embryo is determined by whether the seed of the male comes from the right or the left testicle, and who apparently thought that if one of the testicles is tied up or excised, the offspring produced are all of the same sex-a passage which indicates that some earlier writers were aware of the possibility of putting this theory to the test, even if they evidently assumed the results of such a test to be a foregone conclusion. 
embryo derives nourishment from sucking the side of the womb.' From the Hippocratic texts one may mention first a passage in On the Sacred Disease where the writer refers to the evidence of post-mortem dissections of goats to establish that the 'sacred' disease has a natural, that is a pathological, origin. But two experimental dissections described in On the Heart are especially worth noting. In ch. 2 (L. IX, 80, 9ff.) the writer considers the question of whether any drink passes from the oesophagus via the trachea into the lungs. He remarks that the epiglottis covers the larynx exactly, but suggests nevertheless that a small part of what we drink penetrates by this route into the lungs. This he proves, to his own satisfaction at least, by an experiment in which he stains some water, gives it to a pig to drink, and then cuts open the pig's windpipe as it drinks: 'you will find it stained with the drink', he says, although he notes that 'this is not an operation that the man in the street can undertake'. The theory the writer believes he has proved is in fact incorrect (if the pig's throat was stained, this was no doubt because the animal choked), but the method he uses to verify his theory is exemplary. Nor is this use of the experimental method an isolated example in this work. Later on he refers to another more complicated experiment which met with greater success. Having described the general structure of the heart (where he notices, among other things, that the ventricles and the auricles do not contract simultaneously) ${ }^{2}$ he turns in ch. Io to its 'hidden membranes', giving a brief but exact description of the semi-lunar valves which lie at the base of the aorta and the pulmonary artery. But he not only describes their structure: he investigates their function, showing that if on removing the heart you attempt to force water down either the aorta or the pulmonary artery, the semi-lunar valves will prevent any fluid passing into the ventricles of the heart, and he even notices that the seal formed by the valves is more effective on the left side of the heart (i.e. at the base of the aorta) than on the right (at the base of the pulmonary artery). ${ }^{3}$ It is perhaps not out of place to note that this demonstration of the irreversibility of the flow of the blood out of the heart was an essential (if only a preliminary) step towards the discovery of the circulation of the blood.4

Many other experiments (whether involving the use of dissection or not) might be cited from early Greek investigators in the biological sciences. ${ }^{5}$ But while the extent

I This theory is advanced in On Fleshes, ch. 6, L. vill, 592, II ff., for example, where it is supported by various arguments, e.g. that the new-born baby instinctively knows how to suck.

${ }^{2}$ Ch. 8 , L. IX, 86, 4 ff.

${ }^{3}$ Ch. 10, 86, 13-88, 9. At 88, 6, the writer asserts that not even air can be pumped back through the aorta or pulmonary artery into the heart, but he qualifies this in ch. $12,90,14-92,1$, by suggesting that a little air can and does penetrate into the heart through the pulmonary artery.

4 It is notable that in the De motu cordis et sanguinis in animalibus (1628) Harvey refers frequently not only to Galen, but also to Aristotle and to Hippocrates (mentioning $O_{n}$ the Heart in particular in ch. 17) and among the passages he cites is a text of Galen in which the latter observed that the three semilunar valves placed at the opening of the aorta prevent the return of the blood into the heart.

5 Aristotle, for instance, refers quite often to specimens of different species of animals which were, apparently, deliberately mutilated in order to investigate such questions as whether they can survive without certain organs, whether certain tissues will grow again when excised, or the method of locomotion of different species, e.g. Resp. $47 \mathrm{r} b, 19 \mathrm{ff}$; $479 a, 3 \mathrm{ff}$.; $H A, 519 a, 27 \mathrm{ff}$; $I A, 708 b, 4 \mathrm{ff}$. 
of the researches which had been carried out in such fields as anatomy, zoology and botany by the end of the fourth century B.C. is generally recognized, it is often argued that this is, as it were, the exception that proves the rule-that the fact that men who were mostly trained in the practical art of medicine successfully applied empirical methods to the study of biology shows up all the more dramatically the failure of other Greek theorists to do the same in other fields. Now it is well known that some of the most rigorously empirical texts of early Greek science come from the medical writers (the collections of case histories presented almost without interpretative comment in the Epidemics are the most obvious examples), though equally some of the physiological and pathological treatises of the Hippocratic Corpus are as dogmatic and speculative as any of the cosmological writings of the philosophers. But that some medical theorists, at least, believed there were important differences between their own methods of research and those used in such fields as 'meteorology' is clear from On Ancient Medicine, even though it should be pointed out that in practice, in his own physiological and pathological doctrines, this writer hardly lives up to his expressed ideal of excluding all unwarranted assumptions from the study of medicine. ${ }^{\mathbf{I}}$ Yet notwithstanding the evidence of On Ancient Medicine, the differences between Greek medicine and Greek philosophy in the matter of the attitude towards, and the use of, empirical verification and experimentation may not be so great as is sometimes made out. On the one hand I have already suggested that we should not underestimate the extent to which simple practical tests were carried out in some branches of the physical sciences: the early Greeks took some, if not all, of the most obvious opportunities for experimentation that presented themselves. Nor, on the other hand, should we overestimate the extent to which the medical theorists were able to devise experiments to illuminate the more difficult problems that faced them. ${ }^{2}$ We have seen that some problems in the biological sciences were investigated experimentally with a good deal of success at an early period. But there were, of course, whole areas of physiology, embryology and pathology where the Greeks posed major questions which could not be resolved by the use of dissection or the carrying out of simple rests. It is instructive, then, to consider the methods used, and the results obtained, by the medical theorists in attempting to determine the constituent elements of the body, for example, and to compare these with the work of men who were primarily

I Thus although the writer attacks those who based their pathological theories on the hot, the cold, the wet and the dry, he himself numbers such things as the salty, the bitter, the sweet, the acid and so on among the constituents of the body (ch. 14, CMG, I, 1, 45, 26ff.), and while he criticizes his opponents for oversimplifying the causal principles of diseases (ch. 1, 36, $2 \mathrm{ff}$.) a similar criticism might also be levelled against his own pathological theories, in which he refers,

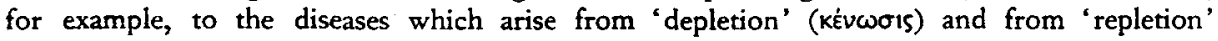
( $\pi \lambda$ inpwa1s) (ch. 10, 42, II ff.).

2 One notable instance where the Greek biologists might have carried out systematic experiments without great difficulty, but failed to do so, is in investigating hybrids (although it should be remarked that for all the interest in heredity in post-Renaissance times the simple experiments of crossing pea-plants which led Mendel to the discovery of the law of the segregation of characters were not performed until the mid-nineteenth century). Equally when the dogma of spontaneous generation was challenged by Redi in the seventeenth century, the experiments he undertook to show that the worms found in decaying meat derive directly from the droppings of flies and not from the putrefaction of the meat itself, were not technically impossible in antiquity. 
cosmologists on the similar, though more general, problem of the elements of physical substances as a whole.

Several Hippocratic writers cite practical tests in conjunction with their theories concerning the elements of the body, although the tests in question are generally quite inconclusive. The author of On Fleshes, for instance, held that we are composed of

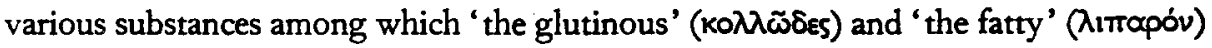
are particularly important, but he suggests that the way we may detect the presence of these in any part or organ of the body is to cook it (when what is 'glutinous' will not readily cook, while what is 'fatty' will). ${ }^{\mathrm{I}}$. This seems to be strictly comparable with the type of observations which appear in the fourth book of the Meteorologica, where the reactions of different substances to being boiled, burned, frozen, etc., are noted down. Then the author of On the Nature of Man refers to certain rather more ambitious tests carried out with drugs to back his theory that the primary constituents of the body are the four humours. First he says that one may discover that these exist as different substances in the body by giving a man different types of drugs, which will draw out phlegm, bile and black bile respectively (ch. 5, L. vi, 42, 6ff.). But then he says that the "clearest proof' that the humours alternate in the body in a cycle according to the seasons is that 'if you will give the same man the same drug four times in the year, his vomit will be most phlegmatic in winter, most liquid in spring, most bilious in summer, and blackest in autumn'.2 Now it is unlikely that the results of the various tests to which this writer refers would correspond at all precisely with those which he describes. Yet even if the tests produced the results he mentions, they would not, of course, prove what he was attempting to establish, for he assumes what is the point at issue, that the humours he had observed, or thought he had observed, in a man's vomit, are elemental. Many other ingenious, but quite undemonstrative, tests are found in the Hippocratic Corpus relating to such topics as the formation of the parts of the body or the pathogenesis of various diseases. ${ }^{3}$ Sometimes simple tests are carried out directly on organic substances from the body: one example has been given from On Fleshes, and elsewhere the same author describes tests on blood taken from a sacrificial victim in connection with his theory that the liver is formed by a process of coagulation. 4 But more often attempts were made to derive information concerning the behaviour of substances in the body by undertaking tests on other, generally simpler, substances outside the body under conditions which were (very roughly) similar. The tests with the intercommunicating vessels, and with different substances put into a bladder full

Ch. 4 , L. vill, $588,25-590,4$.

${ }^{2}$ Ch. 7, esp. 50, 9 ff. Elsewhere too this writer describes the effects of different drugs, e.g. ch. 6,44, in ff.; 46,3 ff.

${ }^{3}$ Several examples from the treatises On Generation, On the Nature of the Child and $O_{n}$ Diseases Iv are discussed by Senn, op. cit. pp. $219 \mathrm{ff}$., and cf. also $O$. Regenbogen, 'Eine Forschungsmethode antiker Naturwissenschaft', Quell. u. Stud. z. Gesch. der Mathematik, Astronomie u. Phy'sik, Abt. B, I (1931), pp. $131 \mathrm{ff}$.

4 Ch.8, L. vin, $594,9 \mathrm{ff}$. He notes that so long as the blood is hot it does not coagulate, but then he also observes that it does not coagulate if it is beaten. Cf. also ch. $9,596,9$ ff., where he remarks that when the 'skin' is removed from blood which is left to clot, another 'skin' forms shortly afterwards (an observation which he uses to support his account of how the skin of the body itself is formed). 
of water and blown on, have al: eady been mentioned, but the Hippocratic writers used these in the former case in illustrate a theory concerning the passage of the humours from one part of the body to another, ${ }^{\mathrm{I}}$ and in the latter case to suggest how the parts of the body are formed by the breath causing like substances to come together. Similarly we find the author of on the Diseases of Women I, for example, illustrating his theory that the flesh of women is more absorbent, because rarer, than the flesh of men, by referring to a test in which equal quantities by weight of unwoven wool and a made-up garment are left suspended over a bowl of water, and the greater absorbency of the unwoven material is shown when the two are collected and reweighed. 3 A number of medical writers undoubtedly recognized the desirability of undertaking tests to corroborate their theories, and indeed tried to do this in practice (even though the accuracy of their observations often leaves much to be desired). In investigating the structure of the body, for example, they used empirical techniques such as dissection most successfully. Yet on such intractable problems as the constituent elements of the body, the formation of the different organs, the origin of diseases and so on, their attempts to make use of practical tests met with little success, for the tests to which they refer were at best inconclusive, and at worst quite irrelevant. Yet if they failed to devise crucial experiments on the more complex problems of physiology, biochemistry and pathology, this was evidently not always for lack of trying: rather their failure must be considered to a large extent inevitable, given that the successful experimental investigation of many of the questions they raised had to wait for (among other things) the development of chemistry.

In conclusion I should summarize the main points I have tried to make in this very compressed discussion of certain features of the role of experiment in early Greek philosophy and medicine. First it seems to me that the question of whether the Greeks experimented cannot be meaningfully discussed in global terms: what we must try to do is to assess the achievements and failures of the Greeks in each branch of scientific inquiry and at each period independently. Secondly, I suggested that even where the failure of the Greeks to experiment is most notorious, that is in the physical sciences, we find that in such fields as acoustics, optics, pneumatics and hydrostatics, quite successful experimental investigations were carried out in antiquiry, and if the most striking successes are all the products of the Alexandrian period or later, the first attempts to undertake simple tests in those fields can be traced back to the fifth or fourth century B.C. Here, where the problems investigated are relatively elementary, and where tests can often be carried out without great difficulty, the Greeks were far from ignoring the experimental method. The early history of mechanics and what we should call chemistry seems to tell a rather different story, but in chemistry the latter

I On Diseases Iv, ch. 39, L. vir, 556,15 ff., suggests that as all the vessels may be filled or emptied by filling or emptying any one of them so the reservoirs ( $\pi \eta \gamma \gamma$ (i) of the humours in the body are filled or emptied by the stomach being filled or emptied.

2 On the Nature of the Child, ch. 17, L. vil, 495, $17 \mathrm{ff}$., argues that growth takes place when the breath, Tveũ $\mu \alpha$, in the body separates the different substances according to their kinds (the dense, the rare and so on), just as the substances put into the bladder (earth, sand, lead-filings) will be found to be sorted according to their kinds when the bladder is left to dry and opened.

${ }^{3}$ Ch. I, L. vIII, 12, 9 ff. It is worth remarking that this test, like that in On Airs, Waters, Places, ch. 8 , mentioned above, p. 59 , n. 2 , involves the use of quancitative measurements. 
part of the fourth century B.C. sees the first detailed collections of data concerning the different properties of substances and their reactions to various simple tests, and such collections of factual information were no negligible achievement, even if they did not lead to the founding of chemical science on a firm basis. And even in mechanics, whatever the apparent shortcomings of Aristotle himself, it is clear from such scanty information as we have concerning his immediate successors that they carried out a number of empirical investigations in this field (and we cannot doubt the success with which these were used for destructive purposes by some of those who opposed the doctrines of Aristotle in late antiquity). Finally, I considered the biological sciences, and here an increasing, and increasingly successful, use of experiment can be traced from the Hippocratic writers and Aristotle, through the Alexandrians Erasistratus and Herophilus, down to Galen.' This is, indeed, generally acknowledged, but it has often been suggested that the use of experimental methods in this field is quite exceptional and due to the fact that these men were, for the most part, trained in the practical discipline of medicine, and this argument (I should submit) has often been exaggerated. On the one hand we should not underestimate the extent to which simple experiments were performed in other fields of science besides biology, and on the other, while there are certainly important differences in outlook and training between some medical theorists and the majority of the philosophers (differences to which On Ancient Medicine draws attention), this is not the only factor to be borne in mind when considering the relative success with which the Greeks applied experimental methods to biology: a more obvious point, but one that may tend to be ignored, is the relative ease with which some theories can be submitted to a practical test in certain branches of the biological sciences (for example in anatomy or embryology, by means of dissections). It will be remembered that the relative ease with which information can be gained in biology is a point which Aristotle stresses in a famous passage in the de Partibus Animalium where he contrasts the study of plants and animals with astronomy. 'We have better means of knowledge', he says, 'concerning the things that perish, that is plants and animals, since we live among them. And anyone that is willing to take sufficient trouble can learn much concerning each one of their kinds."2

A final question arises which must, however, be dealt with summarily. Having suggested that the view prevalent in the nineteenth century, at least, that the Greeks completely failed to experiment, is false, I should say something about how this opinion may have gained currency. Here one might refer to the emphasis often laid on the passages in the Republic ${ }^{3}$ in which Plato argues for the mathematization of astronomy, acoustics and so on, and decries empirical investigation, for while

'I may mention especially the remarkable experiment, described in Anon. Lond. xxxirI, $43 \mathrm{ff}$., in which Erasistratus showed that there are invisible effluvia from animals by keeping a bird in a vessel without food for a given period of time and weighing the animal together with the visible excreta and comparing this with its original weight.

${ }^{2} P A, \mathrm{~A}$, ch. $5,644 b, 28 \mathrm{ff}$. Aristotle suggests that our meagre acquaintance with the heavenly bodies gives us greater joy, but that our knowledge of plants and animals is superior in that we can acquire more and better information about them.

3 E.g. $529 \mathrm{~A}$, ff. and $531 \mathrm{~A}$, ff. 
Plato's view was no doubt influential in antiquity, it did not act as the deterrent that some commentators have supposed. But more important, there is a tendency in several nineteenth-century works on the history of science to assume a constant, linear development of science, and it might be suggested that it was for this reason (among others) that there is a certain reluctance, in many such works, to allow the claims of Greek science whether in respect of methods or of results. That Whewell, for one, experienced a certain difficulty in giving credit where credit is due, may, I think, be seen from a passage from the History of the Inductive Sciences where he discounts the claim of Aristotle to have formed a systematic classification in zoology: 'it would be difficult', Whewell says, ' 'to reconcile such an early maturity of zoology with the conviction which we have had impressed upon us by the other parts of our history, that not only labour but time, not only one man of genius but several, and those succeding each other, are requisite to the formation of any considerable science'.?

KING'S COLLEGE, CAMBRIDGE

G. E. R. LLOYD

\section{S.E.G. IX, 63 AGAIN}

In the last number of these Proceedings (no. 189, n.s. 9, p. 2) Miss Joyce Reynolds discussed this well-known inscription, which is dated in A.D. 2/3 and is incised below a relief of a man reclining on a couch, cup in hand. It was found in the Sanctuary of Apollo at Cyrene in 1925; for a bibliography, see Miss Reynolds's article. The text she prints at the beginning reads as follows:

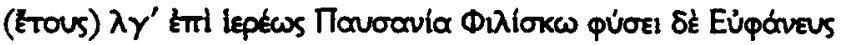

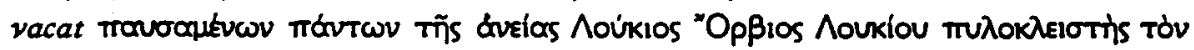

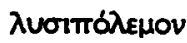

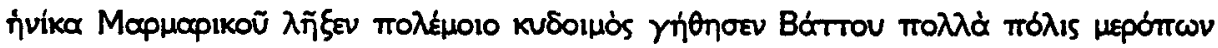
Tĩuos $\measuredangle v[\alpha]$

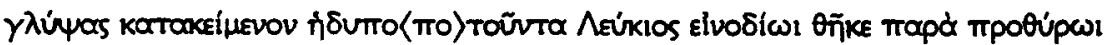

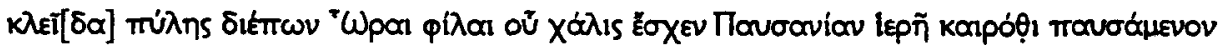

The last sentence raises acute difficulties. It has driven Adolf Wilhelm and Louis Robert to the desperate assumption that we have here one of the rare cases of a spondee standing in place of the penultimate dactyl of a pentameter. Wilhelm read konpoús and

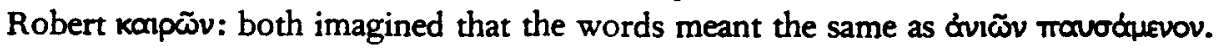
The authority of these two eminent scholars should not prevent us from seeing that the suggestion is ridiculous.

Miss Reynolds has made an important contribution to the solution of this baffling

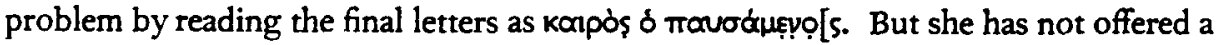
convincing interpretation of the sentence as a whole; the words printed above as oú

' History of the Inductive Sciences from the Earliest to the Present Times (London, 1837), vol. 3, p. 344 .

2 I must express my gratitude to Dr M. B. Hesse, who read and criticized an earlier draft of this paper, and to Dr H. B.F. Dixon and Mr F.H. Sandbach for their advice and comments on particular points. 